Know Your Surgery 


\title{
Know Your Surgery
}

\author{
Anthony E. Stuart \\ Consultant General Surgeon and \\ Surgical Tutor, Oldchurch Hospital, \\ Romford, Essex
}


All rights reserved. No part of this publication may be reproduced or transmitted, in any form or by any means, without permission

First published 1980 by

THE MACMILLAN PRESS LTD

London and Basingstoke

Associated companies in Delhi Dublin

Hong Kong Johannesburg Lagos Melbourne

New York Singapore and Tokyo

\section{Typeset by}

Illustrated Arts, Sutton, Surrey

\section{British Library Cataloguing in Publication Data}

Stuart, Anthony $E$

Know your surgery,

1. Surgery - Problems, exercises, etc.

I. Titte

$617^{\prime} .0076$

RD37

ISBN 978-0-333-25523-0 ISBN 978-1-349-04240-1 (eBook) DOI 10.1007/978-1-349-04240-1

This book is sold subject to the standard conditions of the Net Book Agreement

The paperback edition of this book is sold subject to the condition that it shall not, by way of trade or otherwise, be lent, resold, hired out, or otherwise circulated without the publisher's prior consent in any form of binding or cover other than that in which it is published and without a similar condition including this condition being imposed on the subsequent purchaser 


\title{
FOREWORD
}

\author{
Professor H.D. Ritchie \\ Surgical Unit, The London Hospital
}

Although not the first of its kind, Mr Stuart's volume must be the most exhaustive available, at present, to the surgical student. He has put an enormous amount of careful, painstaking work into the preparation of these questions, and yet managed to make it interesting and at times fun to read. Taken in its full depth, it covers more ground than is needed by the undergraduate, and, as the author points out, is adequate to prepare the young surgeon for the final F.R.C.S. examination.

For those whose mind is stimulated by puzzles (self-assessment!), this volume has much to offer. Few, however experienced they may be, will go through many of its pages without discovering some gaps at least in their knowledge.

$\mathrm{Mr}$ Stuart is surely to be congratulated in making the results of his careful work available generally to the surgical student. 


\section{CONTENTS}

Introduction and Scoring viii

Target Scores $\quad$ ix

Section 1 : Quiz Questions and Multiple Choice Questions 1

1. Surgical Infection 2

2. Neck 6

3. Thyroid and Parathyroid 10

4. Adrenal Glands 14

5. Hernias 18

6. The Breast 22

7. Mouth and Pharynx 26

8. Salivary Glands $\quad 30$

9. Oesophagus 34

10. Stomach and Duodenum 38

11. Intestine 42

12. Appendix 46

13. Colon $\quad 50$

14. Anorectum 54

15. Liver 58

16. Biliary System 62

17. Pancreas 66

18. Spleen $\quad 70$

19. Kidney and Ureter $\quad 74$

20. Bladder 78

21. Prostate 82

22. Penis and Urethra 86

23. Testes and Scrotum 90

24. Vascular Surgery - Arterial 94

25. Vascular Surgery - Veins and Lymphatics 98

26. Fluid and Electrolyte Balance 102

27. Shock 106

28. Hand Surgery 110

29. Orthopaedics 114

30. Fractures 118

31. Head Injuries 122

32. Neurosurgery 126 
33. Oncology 130

34. Thoracic Surgery 134

35. Paediatric Surgery 138

36. Plastic Surgery and Burns 142

37. The Skin 146

38. Otolaryngology 150

39. Gynaecology 154

40. Tropical Surgery 158

41. Surgical Therapeutics 162

42. Surgical Biochemistry 166

43. Surgical Anatomy 170

44. Operative Surgery 174

45. Physical Signs 178

Section 2 : Surgical Mazes $\quad 183$

Section 3 : Differential Diagnosis Countdown 201

Section 4 : The Acute Abdomen - Case Histories A to Z 227

Section 5 : Cryptic Cases A to Z 281 


\section{INTRODUCTION AND SCORING}

This book is designed as a rapid, painless method of both revision and self-assessment in preparing for surgical finals and the F.R.C.S. examination. The material covers the whole range of general surgery and the questions aim to reveal gaps in the student's knowledge and then to help fill these gaps in an entertaining and novel way. Each section is scored and target scores are given to add stimulus and monitor progress.

Although produced for private study, the book may also be effectively used for revision in small groups and will be invaluable for those called upon to teach surgery.

\section{QUIZ QUESTIONS}

Forty-five surgical topics are each covered by twenty quiz questions and five multiple choice questions. The former score 1 to 3 points according to their difficulty. Questions with a 3 score are more relevant to postgraduates (P.G.), but some will be in the range of undergraduates (U.G.) and the separate target scores take this into account. A partially correct answer can be marked accordingly, but no halfmarks should be scored on the questions with a score of 1 .

\section{SCORING THE MCOs}

Each correct answer in the five-part questions scores 1 point. For each wrong answer a mark is deducted. An answer left blank does not penalise - zero is scored.

\section{SURGICAL MAZES}

These 10 tests are a light-hearted variation on multiple choice questions. Correct answers to true-or-false statements lead to a rapid path through the mazes, whereas two consecutive wrong answers will lead to a back-track, to guarantee you get it right next time!

\section{DIFFERENTIAL DIAGNOSIS COUNTDOWN}

Differential diagnosis of important symptoms and signs is important in surgical practice. See how you score on these 330 causes of 60 presenting features.

\section{ACUTE ABDOMEN AND CRYPTIC CASES}

Test your surgical knowledge and clinical acumen in diagnosing these $\mathbf{5 2}$ simulated case histories. Starting with a presenting complaint and a list of the clinical features available to you, decide what is the most relevant information to reach a correct diagnosis. All of the acute abdomen cases can be successfully diagnosed without turning to the investigations.

To score the case diagnoses start with the presenting complaint and a score of 25 and deduct 1 point for each item of information you require to arrive at the diagnosis (that is 1 point for each page turned to). As soon as you make a diagnosis, write it down with your score and work through the remaining clinical features. Should you need to revise your diagnosis in the light of more information, deduct a further 3 points from your score. Compare your scores with the targets. 


\begin{tabular}{|c|c|c|c|c|c|c|c|c|c|}
\hline No. & Subject title & U.G. & P.G. & 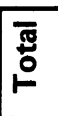 & No. & Subject title & U.G. & P.G. & . \\
\hline 1. & Infection & 21 & 28 & 41 & 24. & Vascular - Arterial & 18 & 29 & 41 \\
\hline 2. & Neck & 22 & 30 & 40 & 25. & Veins \& lymphatics & 20 & 30 & 43 \\
\hline 3. & Thyroid & 21 & 29 & 41 & 26. & Fluid & 17 & 26 & 42 \\
\hline 4. & Adrenal glands & 19 & 27 & 48 & 27. & Shock & 17 & 26 & 41 \\
\hline 5. & Hernias & 21 & 30 & 41 & 28. & Hand surgery & 18 & 28 & 41 \\
\hline 6. & Breast & 20 & 29 & 39 & 29. & Orthopaedics & 18 & 27 & 41 \\
\hline 7. & Mouth \& pharynx & 18 & 28 & 42 & 30. & Fractures & 18 & 27 & 42 \\
\hline 8. & Salivary glands & 18 & 28 & 43 & 31. & Head injuries & 18 & 29 & 45 \\
\hline 9. & Oesophagus & 21 & 31 & 44 & 32. & Neurosurgery & 17 & 27 & 39 \\
\hline 10. & Stomach & 21 & 30 & 40 & 33. & Oncology & 18 & 27 & 42 \\
\hline 11. & Intestine & 21 & 30 & 40 & 34. & Thoracic surgery & 21 & 30 & $4 \mathrm{~s}$ \\
\hline 12. & Appendix & 23 & 32 & 42 & 35. & Paediatric surgery & 18 & 28 & 41 \\
\hline 13. & Colon & 20 & 29 & 39 & 36. & Plastic surgery & 18 & 28 & 37 \\
\hline 14. & Anorectum & 20 & 30 & 39 & 37. & Skin & 18 & 28 & 41 \\
\hline 15. & Liver & 19 & 29 & 43 & 38. & Otolaryngology & 18 & 27 & 40 \\
\hline 16. & Biliary system & 18 & 28 & 40 & 39. & Gynaecology & 17 & 26 & 43 \\
\hline 17. & Pancreas & 21 & 31 & 49 & 40. & Tropical surgery & 17 & 28 & 43 \\
\hline 18. & Spleen & 19 & 28 & 45 & 41. & Therapeutics & 18 & 18 & 39 \\
\hline 19. & Kidney \& ureter & 18 & 28 & 38 & 42. & Biochemistry & 21 & 28 & 43 \\
\hline 20. & Bladder & 19 & 29 & 44 & 43. & Anatomy & 17 & 26 & 41 \\
\hline 21. & Prostate & 18 & 29 & 41 & 44. & Operative surgery & 16 & 26 & 38 \\
\hline 22. & Penis \& urethra & 18 & 28 & 40 & & & & & \\
\hline 23. & Testes and scrotum & 19 & 28 & 37 & & & & & \\
\hline
\end{tabular}




\section{MULTIPLE CHOICE QUESTIONS}

Each correct answer scores 1 point; for every wrong answer deduct 1 point, any blanks count as 0 .

\begin{tabular}{|r|l|r|r|r|l|r|r|}
\hline No. & \multicolumn{1}{|c|}{ Subject title } & U.G. & P.G. & No. & Subject title & U.G. & P.G. \\
\hline 1. & Surgical infection & 13 & 18 & 24. & Vascular surgery & & \\
2. & Neck & 10 & 16 & & - Arterial & 11 & 17 \\
3. & Thyroid \& parathyroid & 10 & 16 & 25. & Veins \& lymphatics & 16 & 21 \\
4. & Adrenal glands & 12 & 17 & 26. & Fluid & 11 & 17 \\
5. & Hernias & 15 & 19 & 27. & Shock & 14 & 19 \\
6. & The breast & 9 & 15 & 28. & Hand surgery & 13 & 19 \\
7. & Mouth \& pharynx & 14 & 19 & 29. & Orthopaedics & 13 & 18 \\
8. & Salivary glands & 10 & 15 & 30. & Fractures & 11 & 16 \\
9. & Oesophagus & 11 & 16 & 31. & Head injuries & 12 & 18 \\
10. & Stomach \& duodenum & 13 & 18 & 32. & Neurosurgery & 10 & 15 \\
11. & Intestine & 14 & 19 & 33. & Oncology & 15 & 20 \\
12. & Appendix & 15 & 20 & 34. & Thoracic surgery & 14 & 20 \\
13. & Colon & 14 & 19 & 35. & Paediatric surgery & 12 & 17 \\
14. & Anorectum & 10 & 15 & 36. & Plastic surgery & 14 & 19 \\
15. & Liver & 13 & 18 & 37. & The skin & 14 & 19 \\
16. & Biliary system & 11 & 16 & 38. & Otolaryngology & 13 & 18 \\
17. & Pancreas & 11 & 17 & 39. & Gynaecology & 10 & 15 \\
18. & Spleen & 12 & 17 & 40. & Tropical surgery & 9 & 14 \\
19. & Kidney \& ureter & 13 & 18 & 41. & Therapeutics & 16 & 21 \\
20. & Bladder & 15 & 20 & 42. & Biochemistry & 14 & 19 \\
21. & Prostate & 10 & 16 & 43. & Anatomy & 10 & 15 \\
22. & Penis \& urethra & 13 & 18 & 44. & Operative surgery & 13 & 19 \\
23. & Testes \& scrotum & 11 & 17 & 45. & Physical signs & 7 & 10 \\
\hline
\end{tabular}


DIFFERENTIAL DIAGNOSIS COUNTDOWN

\begin{tabular}{|c|c|c|c|}
\hline Countdown & Total & U.G. & P.G. \\
\hline No. 1 & 55 & 45 & 50 \\
No. 2 & 55 & 44 & 49 \\
No. 3 & 55 & 42 & 47 \\
No. 4 & 55 & 43 & 48 \\
No. 5 & 55 & 44 & 49 \\
No. 6 & 55 & 42 & 47 \\
\hline
\end{tabular}

\section{ACUTE ABDOMEN}

\begin{tabular}{|c|c|c|c|c|c|}
\hline Case & U.G. & P.G. & Case & U.G. & P.G. \\
\hline A & 15 & 18 & N & 15 & 17 \\
B & 13 & 16 & $O$ & 14 & 16 \\
C & 16 & 19 & P & 13 & 15 \\
D & 15 & 18 & Q & 14 & 16 \\
E & 14 & 17 & R & 10 & 13 \\
F & 18 & 20 & S & 10 & 13 \\
G & 11 & 13 & T & 12 & 14 \\
H & 12 & 14 & U & 13 & 15 \\
I & 10 & 12 & V & 10 & 12 \\
J & 11 & 14 & W & 10 & 12 \\
K & 10 & 12 & $X$ & 11 & 13 \\
L & 13 & 15 & Y & 12 & 14 \\
M & 14 & 16 & Z & 12 & 14 \\
\hline
\end{tabular}


CRYPTIC CASES

\begin{tabular}{|c|c|c|c|c|c|}
\hline Case & U.G. & P.G. & Case & U.G. & P.G. \\
\hline A & 8 & 11 & N & 11 & 14 \\
B & 9 & 12 & $O$ & 10 & 13 \\
C & 10 & 13 & P & 11 & 14 \\
D & 10 & 13 & Q & 12 & 15 \\
E & 10 & 13 & R & 12 & 15 \\
F & 11 & 14 & S & 13 & 16 \\
G & 9 & 12 & T & 10 & 13 \\
H & 8 & 11 & U & 9 & 12 \\
I & 7 & 10 & V & 10 & 13 \\
J & 10 & 13 & W & 13 & 16 \\
K & 11 & 14 & $X$ & 9 & 12 \\
L & 12 & 15 & Y & 10 & 13 \\
M & 12 & 15 & Z & 13 & 16 \\
\hline
\end{tabular}

